\title{
Controversial predictors of biochemical recurrence after radical prostatectomy: a study from a Latin American (Brazilian) Institution
}

Marcelo R. Noronha, Maisa M. Q. Quintal, Luis A. Magna, Leonardo 0. Reis, Athanase Billis, Luciana R. Meirelles

Department of Pathology (MRN, MMQQ, AB, LRM); Department of Medical Genetics/Biostatistics (LAM) and Department of Urology (LOR), School of Medical Sciences, State University of Campinas (Unicamp), Campinas, Brazil

\section{ABSTRACT}

Purpose: To analyze controversial clinicopathologic predictors of biochemical recurrence after surgery: age, race, tumor extent on surgical specimen, tumor extent on needle biopsy, Gleason score $3+4$ vs $4+3$, and amount of extent of extraprostatic extension and positive surgical margins.

Materials and Methods: The needle biopsies and the correspondent surgical specimens were analyzed from 400 patients. Time to recurrence was analyzed with the Kaplan-Meier curves and risk of shorter time to recurrence using Cox univariate and multivariate analysis.

Results: Except for age, race, maximum percentage of cancer per core, and number of cores with cancer, all other variables studied were significantly predictive of time to biochemical recurrence using the Kaplan-Meier curves. In univariate analysis, except for focal extraprostatic extension, age, race, focal positive surgical margins, and maximum extent and percentage of cancer per core, all other variables were significantly predictive of shorter time to recurrence. On multivariate analysis, diffuse positive surgical margins and preoperative PSA were independent predictors.

Conclusions: Young patients and non-whites were not significantly associated with time to biochemical recurrence. The time consuming tumor extent evaluation in surgical specimens seems not to add additional information to other well established predictive findings. The higher predictive value of Gleason score $4+3=7$ vs $3+4=7$ discloses the importance of grade 4 as the predominant pattern. Extent and not simply presence or absent of extraprostatic extension should be informed. Most tumor extent evaluations on needle biopsies are predictive of time to biochemical recurrence, however, maximum percentage of cancer in all cores was the strongest predictor.

\section{ARTICLE INFO}

\section{Key words:}

Biochemical Processes;

Recurrence; Prostate; Prostate-Specific Antigen;

Prostatectomy; Prostatic

Neoplasms

Int Braz J Urol. 2013; 39: 779-92

Submitted for publication: April 12, 2013

Accepted after revision:

July 04, 2013

\section{INTRODUCTION}

While the overall survival of surgically treated prostate cancer patients remains excellent, nearly
$30 \%$ of patients treated definitively will have biochemical recurrence (BR), defined as prostate-specific antigen (PSA) $\geq 0.2 \mathrm{ng} / \mathrm{ml}$ according to recommendation of the American Urological Association (1). 
There are well established clinical and pathological predictors of BR after radical prostatectomy (RP), including preoperative serum PSA, pathological tumor stage, Gleason histological grade, and positive surgical margins (2). However, other features are controversial predictors, which are the aim of our study.

The influence of age in the biological aggressiveness of prostate cancer is controversial (3-6). Some studies suggest that prostatic carcinoma has worse outcome with increasing age while others suggest that young age is an adverse prognostic factor.

Prostate cancer may be biologically more aggressive among Black men though controversial (7-11). The prevalence of prostate cancer in Brazil is higher in Black men compared to White men (1215). We studied the influence of race in regard to biochemical recurrence after radical prostatectomy.

Extent of tumor on needle biopsy may be useful to predict extent of cancer in RP, surgical margin status, pathological stage, and tumor recurrence. There are several ways to evaluate tumor extent on biopsy: number and percentage of positive cores, total linear length and percentage of carcinoma in all cores, length and percentage of carcinoma in a single core, and others. The controversy is related to which is the best predictor method (16-18).

One of the most controversial aspects of the pathological assessment of RP specimens is the measurement of tumor volume or extent. There is consensus that tumor volume or extent by itself correlates with adverse findings at RP (19). The critical and controversial question concerns whether tumor volume or extent in RP is an independent prognostic parameter for BR after RP once other routinely variables are accounted for (20).

Tumors with a Gleason score of 7 have significantly worse prognosis than those with a Gleason score $\leq 6$. Given the adverse prognosis associated with Gleason pattern 4, one would expect whether a tumor Gleason score $3+4=7$ or $4+3$ $=7$ would influence prognosis, however this issue is controversial (21-23).

Extraprostatic extension (EPE) and positive surgical margins (PSM) have prognostic importance in most studies (24-26) and may influence therapeutic options after surgery. However, the amount of EPE and PSM seems to be more important than a simple report of presence or absence of these pathological findings. An additional concern is the absence of consensus among pathologists how to evaluate the amount of EPE and PSM $(27,28)$.

\section{MATERIALS AND METHODS}

This retrospective study was based on needle biopsies and correspondent surgical specimens of 400 consecutive patients submitted to retropubic RP from 1997 to 2011 at an institution located in the southeast region of Brazil. The clinical variables studied included age, race, and preoperative serum PSA; the pathological variables included tumor extent on needle biopsy; and, in surgical specimens tumor extent, Gleason score, seminal vesicle invasion, extraprostatic extension and positive surgical margins. According to race, patients were considered Whites and African-Brazilians. In Brazil African-Brazilians include Mulattos (White and African-Brazilian admixture). Five patients of oriental ancestry were excluded. Some other missing data are not included in the tables. Age was categorized as $\leq 55$ years and > 55 years. All other continuous data were categorized by the median value.

Linear carcinoma extent in $\mathrm{mm}$ on needle prostatic biopsy was measured using a single Olympus (Olympus Optical Co., Ltd., Tokyo, Japan) micrometer eyepiece with a linear array. In cases of discontinuous foci $1 \mathrm{~mm}$ apart, the tumor was considered as continuous and the measure included 1 $\mathrm{mm}$. In discontinuous foci more than $1 \mathrm{~mm}$ apart, the final extent was the sum of the measures. Tumor extent on biopsies was evaluated as: number and percentage of cores with carcinoma, total length and percentage of carcinoma in all cores, and maximum length and percentage of cancer per core.

After RP, serum PSA was measured every 3 months during year 1, every 6 months during year 2 and annually thereafter. No patient in this series received radiotherapy or androgen manipulation before or after surgery. Total serum PSA was measured using the previously validated Immulite ${ }^{\circledR}$ PSA kit. Postoperative biochemical recurrence (BR) was considered PSA $0.2 \mathrm{ng} / \mathrm{mL}$ or greater according to the American Urological Association 
recommendation (1). Patients without BR were censored at last follow-up. The study was approved by our institutional committee of ethics.

Surgical specimens were step sectioned at 3 to $5 \mathrm{~mm}$ intervals and embedded in paraffin. A mean of 32 paraffin blocks was processed. Sections $(6 \mu \mathrm{m})$ of each block were stained with hematoxylin and eosin. Each transverse section of the prostate was subdivided into 2 anterolateral and 2 posterolateral quadrants. Using the cone method, 8 sections from the bladder neck and 8 from the apex were obtained.

PSM was defined as cancer cells in contact with the inked specimen surface. PSM was considered focal whenever present up to 1 quadrant and/or sections from the bladder neck or apex and diffuse in more than 1 quadrant or sections.

EPE was diagnosed when cancer was seen in adipose tissue, and in case of a desmoplastic response when a protuberance corresponding to tumor extension into periprostatic tissue was observed. EPE was considered focal whenever present up to 1 quadrant of the transverse sections and/or sections from the bladder neck or apex and diffuse in more than 1 quadrant or sections. Seminal vesicle invasion occurred when there was involvement of the muscular coat.

Tumor extent at RP was evaluated by a previously described semiquantitative point count method (29). Briefly, each quadrant of the transverse sections was drawn on paper and contained 8 equidistant points. During microscopic examination of the slides, the tumor area was drawn on the correspondent quadrant on the paper. At the end of examination, the number of positive points represented an estimate of the tumor extent.

Histological tumor grading was performed according to the revised Gleason grading system (30). Gleason score was categorized as $\leq 6,3+4$ $=7,4+3=7, \geq 8$. All cases were reviewed by a senior uropathologist $(\mathrm{AB})$.

\section{Statistical analysis}

Time to biochemical recurrence (TBR) was analyzed with the Kaplan-Meier product-limit analysis using the log-rank test for comparison between the groups. Univariate and multivariate Cox stepwise logistic regression models were used to identify significant predictors of shorter TBR. Two-sided $P$ value $<0.05$ was considered statistically significant. All statistical analyses were performed using PASW ${ }^{\circledR}$ Statistics 18.0.

\section{RESULTS}

Table-1 shows the clinicopathologic characteristics of 400 studied patients submitted to radical prostatectomy.

After RP 128 of the 400 men (32.0\%) experienced BR at a mean follow-up of 21 months (median 10, range 3 to 129). Of the remaining patients 253 (63.2\%) who were censored remained at risk at a mean follow-up of 53 months (median 48, range 3 to 155), while 19 (4.8\%) had no serum PSA data available.

Table-2 shows the Kaplan-Meier product-limit analysis for TBR following RP according to several clinicopathologic characteristics. There was no statistical significant difference for age (log-rank, $p=0.997$ ), race (log-rank, $p=0.547$ ), maximum percentage of cancer per core (log-rank, $p$ $=0.313)$, number of cores with cancer (log-rank, $p$ $=0.138$ ), absent vs focal EPE (log-rank, $p=0.892$ ), and absent vs focal PSM (log-rank, $p=0.069$ ).

Percentage extent in $\mathrm{mm}$ of cancer in all cores was the strongest predictor of TBR (log-rank, $p=0.001$ ) (Figure-1). Tumor extent of tumor in RP evaluated as positive points was significantly associated with TBR (log-rank, $\mathrm{p}=0.017$ ) (Figure-2). Gleason score in RP categorized as $\leq 6,3+4=$ $7,4+3=7$, and $\geq 8$ was significantly associated with TBR (Figure-3). There is almost an overlap comparing the curves of Gleason score $4+3=7$ and Gleason score $\geq 8$. Diffuse EPE (log-rank, $p<$ 0.001 ) and diffuse PSM (log-rank, $p<0.001)$ were significantly associated with shorter TBR.

Table-3 shows the Cox univariate and multivariate proportional hazard analysis of several clinicopathologic characteristics predicting TBR after RP. Except for focal EPE ( $p=0.893)$, age $(p=$ $0.796)$, race $(p=0.550)$, focal PSM ( $p=0.445)$, maximum extent of cancer per core $(p=0.133)$ and maximum percentage extent of cancer per core (p $=0.065$ ), all other characteristics had a significantly risk for shorter TBR. 
For multivariate analysis, we included only the statistically significant characteristics of univariate analysis using the backward stepwise logistic regression method. For tumor extent evaluation on needle biopsy, we included the strongest predictor (percentage of cancer extent in all cores). Only diffuse PSM $(\mathrm{p}<0.001)$ and preoperative PSA $(\mathrm{p}=0.034)$ were independent predictors of shorter TBR. Seminal vesicle invasion showed a trend toward significance $(\mathrm{p}=0.060)$.

\section{DISCUSSION}

\section{Age}

The influence of age in the biological aggressiveness of prostate cancer is controversial. Carter et al. (3) and Herold et al. (4) suggest that prostatic carcinoma is higher grade and has worse outcome with increasing age. However, the data are conflicting on this issue. Bauer et al. (5) and Catalona and Smith (6) have not found age to be related to outcome. Parker et al. (31) in a meta-analysis of 34 studies which included a total of 27551 patients concluded that evidence suggests that young age was an adverse prognostic factor in some series of radiation therapy before the advent of PSA assays, when men typically presented clinically with locally advanced disease, but that age has no significant prognostic effect in contemporary series of localized prostate cancer. In our study, TBR was not statistically different comparing patients $\leq 55$-year-old vs $>$ 55-year-old.

\section{Race}

Prostate cancer may be biologically more aggressive among Black men though controversial (7-9). In a study by Cross et al. (10), even though African-American men presented at a younger age and with more advanced disease compared with White men with prostate cancer, PSA outcome after RP when controlled for known clinical predictive factors was not statistically different. Freedland et al. (11) described no differences between Black and White men in the preoperative clinical factors or the pathologic features of the $\mathrm{RP}$ specimens and race was not an independent predictor of biochemical recurrence.
The existence of racial differences in prostate carcinoma treatment outcomes remains controversial and although Latino patients/Hispanic race were included in one report (32), our study is unique dealing with this issue in a Latin American (Brazilian) country. The frequency of non-Whites in our study (19.7\%) is similar to this population in the southeast region of Brazil. The results of our cohort of patients showed that race is not significantly associated with TBR following surgery.

In contrast to the bifurcated United States model, where Blacks and Whites are clearly separate groups, with Blacks defined as those with any African ancestry, racial classification in Brazil is far more complex, ambiguous, and fluid. Non-Whites in Brazil includes an intermediate Brown (pardo) category along a white-to-black color continuum, often used as a proxy for mulattos or persons with White and Black admixture (14).

\section{Tumor extent in radical prostatectomy}

One of the most controversial aspects of the pathological assessment of radical prostatectomy specimens is the measurement of tumor volume or extent. Some institutions have accurately calculated the tumor volume through computer-assisted image analysis systems (33). As this method is not feasible for routine clinical practice, there are alternative simpler means for measuring tumor extent. We applied a practical method for estimating tumor extent in RP, which can be used by any general pathologist in the laboratory (29).

There is consensus that tumor volume or extent by itself correlates with adverse findings at RP, such as Gleason score, clinicopathological stage, seminal vesicle invasion, extraprostatic extension and margins of resection (19). The critical and controversial question concerns whether tumor volume is an independent prognostic parameter once other routinely assessed variables are accounted for (20). In our study, tumor extent in radical prostatectomy was significantly associated with TBR in univariate analysis $(p=0.004)$, however in multivariate analysis was not significant $(p=0.633)$. The result favors that this time consuming report in surgical specimens seems not to add additional information to other well established predictive findings. 
Table 1 - Clinicopathologic characteristics of $\mathbf{4 0 0}$ study patients submitted to radical prostatectomy for prostate cancer. SD, standard deviation.

Characteristic

\section{Age (years)}

mean \pm SD

median

range

Race

Whites

Non-whites

Preoperative PSA (ng/mL)

mean \pm SD

median

range

Number of cores

mean $\pm \mathrm{SD}$

median

range

Number of cores with cancer

mean $\pm \mathrm{SD}$

median

range

Percentage of cores with cancer

mean \pm SD

median

range

Extent of cancer in all cores

$$
\begin{aligned}
& \text { mean } \pm \mathrm{SD} \\
& \text { median } \\
& \text { range }
\end{aligned}
$$

Percentage of cancer in all cores

$$
\mathrm{n}(\%)
$$

$$
63 \pm 6.62
$$

64

$$
43-76
$$

$$
9.84 \pm 6.80
$$$$
8.00
$$

$0.28-51$

$10 \pm 3.71$

11

$2-20$

$$
\begin{gathered}
3 \pm 2.03 \\
2 \\
1-13
\end{gathered}
$$

31

$$
9 \pm 9.49
$$

6

$$
1-62
$$


continuation

mean \pm SD

$18.5 \pm 18.28$

median

12

range

$0.4-100$

Maximum extent of cancer per core

mean $\pm \mathrm{SD}$

$4 \pm 3.31$

median

3.5

range

$1-20$

Maximum percentage of cancer per core

mean $\pm \mathrm{SD}$

$51.58 \pm 30.14$

median

47

range

$1-100$

Gleason score in RP

$\leq 6$

$134(33.8)$

$3+4=7$

$186(46.9)$

$4+3=7$

$53(13.4)$

$\geq 8$

$24(6.0)$

Tumor extent in RP (positive points)

mean $\pm \mathrm{SD}$

median

range

$1-225$

Seminal vesicle invasion

absent

present

$41(10.4)$

Extraprostatic extension

absent

$254(64.0)$

focal

$40(10.1)$

diffuse

$103(25.9)$

Positive surgical margins

absent

$213(53.5)$

focal

49 (12.3)

diffuse

$136(34.2)$ 
Table 2 - Kaplan-Meier product-limit analysis for time to biochemical recurrence following radical prostatectomy according to several clinicopathologic characteristics.

Characteristic

$X^{2}$

$<0.001$

0.997

Log-rank, $p$

0.547

Whites vs non-Whites

.363

Age (years)

$\leq 55$ vs $>55$

1.017

0.313

$\leq 47 \%$ vs. $>47 \%$

Number of cores with cancer

$$
\leq 2 \text { vs. }>2
$$

Tumor extent in RP

$\leq 27$ positive points vs $>27$ positive points

5.726

0.017

Maximum extent of cancer per core

$\leq 3.5 \mathrm{~mm}$ vs. $>3.5 \mathrm{~mm}$

Percentage of cores with cancer

$$
\leq 31 \% \text { vs. }>31 \%
$$

Extent of cancer in all cores

$$
\leq 6 \mathrm{~mm} \text { vs. }>6 \mathrm{~mm}
$$

Percentage of cancer in all cores

$$
\leq 12 \% \text { vs }>12 \%
$$

Extraprostatic extension

absent vs diffuse

12.430 $<0.001$

absent vs focal

0.018

0.892 
continu ation

Gleason score in RP

$\leq 6$ vs $3+4=7$ vs $4+3=7$ vs $\geq 8$

Preoperative PSA (ng/mL)

$\leq 10$ vs $>10$

Seminal vesicle invasion

absent vs present

$<0.001$

Positive surgical margins

absent vs focal vs. diffuse

33.562

$<0.001$

absent vs focal

5.350

0.069

Figure 1 - Kaplan-Meier product-limit analysis shows time to PSA biochemical progression-free outcome by the median value of percentage of cancer extent in $\mathrm{mm}$ in all cores. Cum, cumulative.

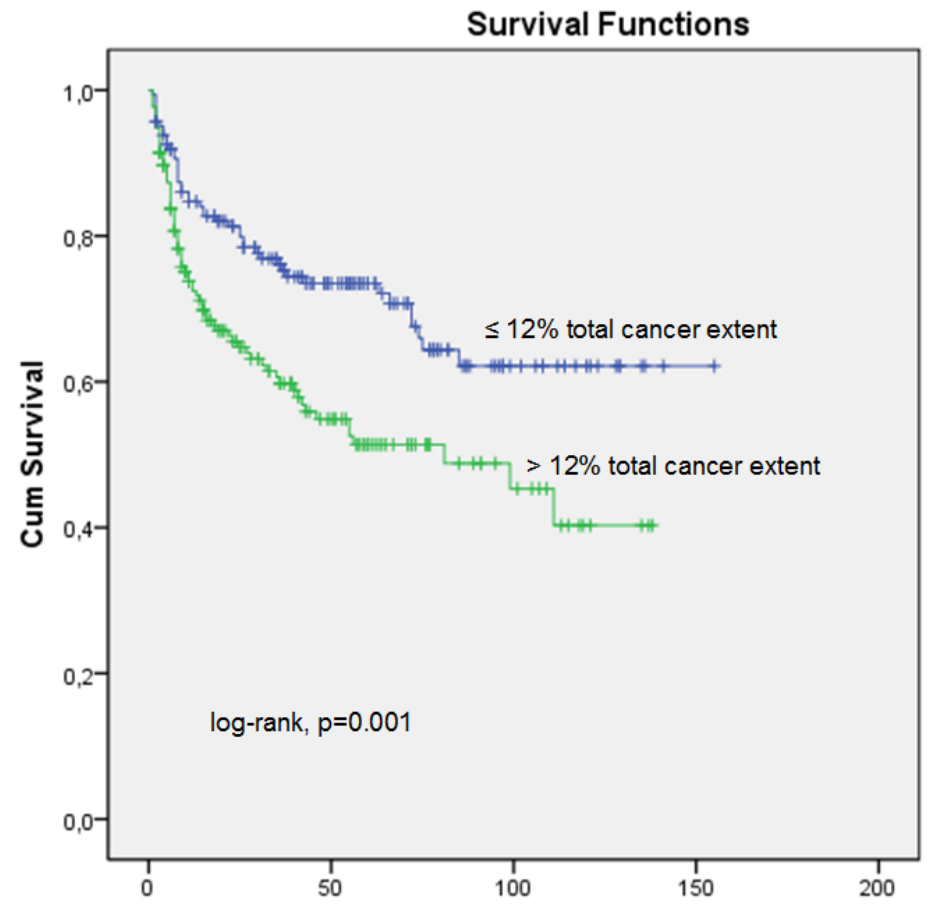


Figure 2 - Kaplan-Meier product-limit analysis shows time to PSA biochemical progression-free outcome by the median value of tumor extent evaluated as positive points in surgical specimens. Cum, cumulative.

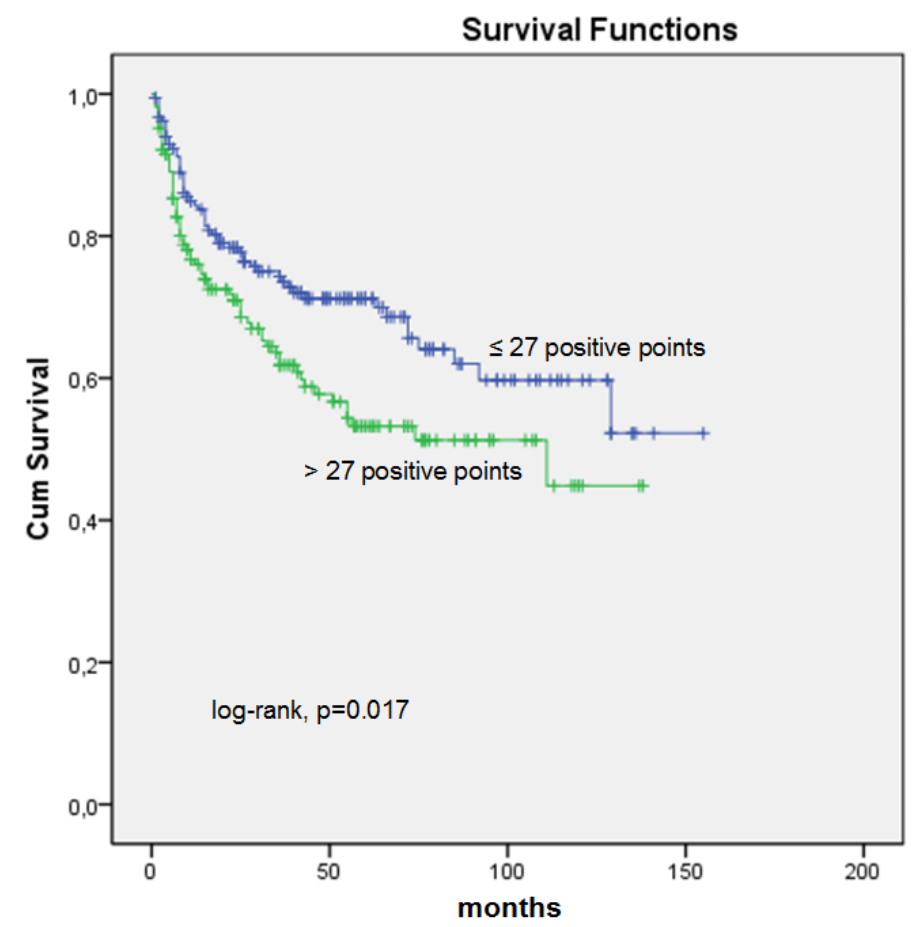

Figure 3 - Kaplan-Meier product-limit analysis shows time to PSA biochemical progression-free outcome by Gleason score $\leq$ $6,3+4=7,4+3=7$, and $\geq 8$ in surgical specimens. Cum, cumulative.

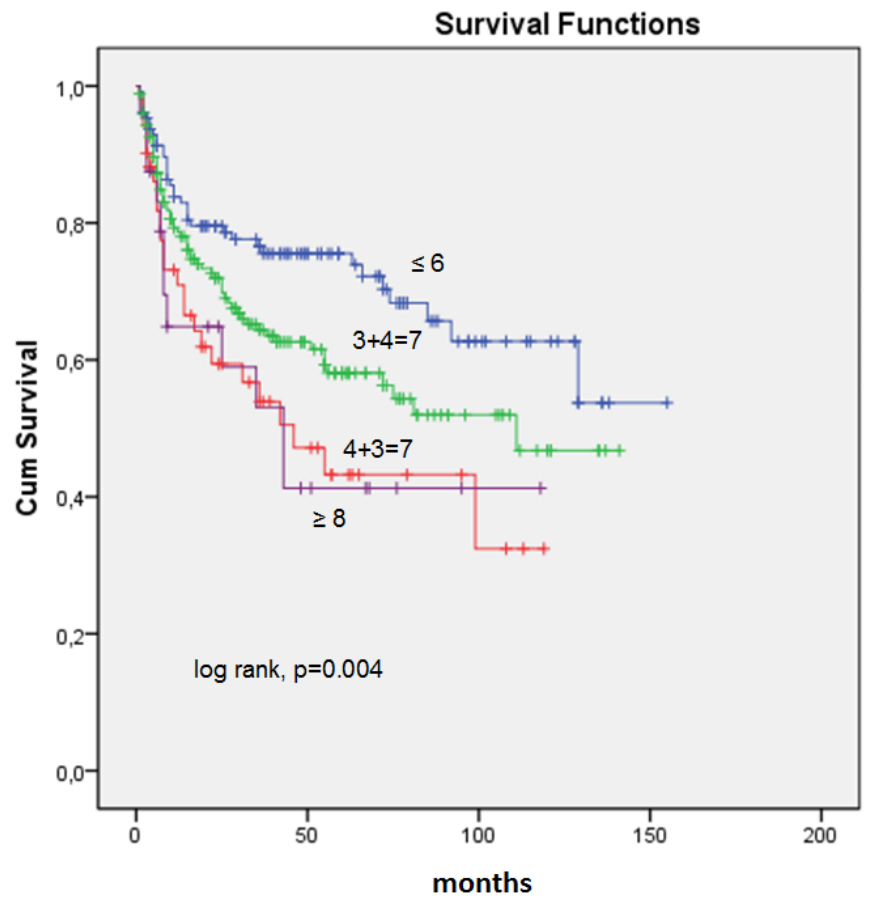


Table 3 - Cox univariate and multivariate proportional hazard analysis of several clinicopathologic characteristics predicting shorter time to biochemical recurrence following radical prostatectomy. $\mathrm{Cl}$, confidence interval.

\begin{tabular}{|c|c|c|c|}
\hline Characteristic & Hazard ratio $(95 \% \mathrm{Cl})$ & Wald test & $\mathrm{p}$ \\
\hline \multicolumn{4}{|l|}{ Univariate analysis } \\
\hline Focal EPE & $1.040(0.588-1.841)$ & 0.018 & 0.893 \\
\hline Age & $0.997(0.972-1.022)$ & 0.067 & 0.796 \\
\hline Race & $0.876(0.567-1.352)$ & 0.358 & 0.550 \\
\hline Focal PSM & $1.258(0.698-2.270)$ & 0.583 & 0.445 \\
\hline Maximum extent of cancer per core & $1.035(0.990-1.082)$ & 2.259 & 0.133 \\
\hline Maximum percentage of cancer per core & $1.006(1.000-1.011)$ & 3.417 & 0.065 \\
\hline Extent of cancer in all cores & $1.018(1.003-1.034)$ & 5.323 & 0.021 \\
\hline Number of cores with cancer & $1.092(1.014-1.176)$ & 5.395 & 0.020 \\
\hline Percentage of cores with cancer & $1.009(1.002-1.016)$ & 7.089 & 0.008 \\
\hline Tumor extent in RP & $1.006(1.002-1.011)$ & 8.299 & 0.004 \\
\hline Gleason score in RP & $1.394(1.130-1.721)$ & 9.581 & 0.002 \\
\hline Percentage of cancer in all cores & $1.014(1.005-1.022)$ & 10.381 & 0.001 \\
\hline Diffuse EPE & $1.375(1.147-1.649)$ & 11.843 & 0.001 \\
\hline Preoperative PSA & $1.042(1.025-1.060)$ & 22.672 & $<0.001$ \\
\hline Seminal vesicle invasion & $2.888(1.880-4.437)$ & 23.431 & $<0.001$ \\
\hline Diffuse PSM & $1.651(1.382-1.972)$ & 30.523 & $<0.001$ \\
\hline \multicolumn{4}{|l|}{ Multivariate analysis } \\
\hline Gleason score in RP & $1.143(0.653-2.001)$ & 0.220 & 0.639 \\
\hline Tumor extent in RP & $0.882(0.526-1.478)$ & 0.228 & 0.633 \\
\hline Diffuse EPE & $0.874(0.672-1.137)$ & 1.011 & 0.315 \\
\hline Percentage of cancer in all cores & $1.293(0.822-2.035)$ & 1.238 & 0.266 \\
\hline Seminal vesicle invasion & $1.730(0.978-3.061)$ & 3.544 & 0.060 \\
\hline Preoperative PSA & $1.601(1.035-2.474)$ & 4.477 & 0.034 \\
\hline Diffuse PSM & 1.734 (1.371-2.192) & 21.128 & $<0.001$ \\
\hline
\end{tabular}




\section{Gleason score in radical prostatectomy}

Tumors with a Gleason score of 7 have significantly worse prognosis than those with a Gleason score $\leq 6$. Given the adverse prognosis associated with Gleason pattern 4, one would expect whether a tumor Gleason score $3+4=7$ or $4+3$ $=7$ would influence prognosis. No significant survival advantage was reported for Gleason score 3 $+4=7$ over $4+3=7$ by Oefelein et al. (21). Other investigators have shown that Gleason score $4+$ $3=7$ has a worse prognosis than Gleason score 3 $+4=7(18,19)$. Due to this controversy, the prognostic Gleason grouping according to score may be either $\leq 6,7, \geq 8$ or $\leq 6,3+4=7,4+3=7, \geq 8$. In our cohort of patients the Kaplan-Meier curve showed that the Gleason score $4+3=7$ behaved similarly to score $\geq 8$ and different to score $3+4$ $=7$. This result discloses the importance of grade 4 as the predominant pattern and favors a 4 score prognostic grouping: $\leq 6,3+4=7,4+3=7$, and $\geq 8$. Gleason score in our study was significantly predictive of TBR in univariate analysis but not in multivariate analysis probably due to fewer cases in the prognostic groups $4+3=7$ and $\geq 8$. Another limitation could be the relatively short mean follow-up time.

\section{Extraprostatic extension and positive surgical margins}

Extraprostatic extension and positive surgical margins have prognostic importance and may influence therapeutic options after surgery. However, the amount of EPE and PSM seems to be more important than a simple report of presence or absence of these pathological findings (24-26).

During the International Society of Urological Pathology (ISUP) consensus conference on handling and staging of radical prostatectomy specimens held in Boston during the 98th meeting of the United States and Canadian Academy of Pathology (USCAP), no consensus could be reached as to how evaluate extent of EPE and PSM $(27,28)$. In this study we evaluated the influence of focal and diffuse EPE and PSM on TBR using a simple method for EPE and PSM extent quantitation that can be used in the daily practice of all pathologists who step section and totally process the surgical specimen. Considering that in the 2009 version of the TNM Classification of Malignant Tumors microscopic involvement of the bladder neck is pT3a, in our study this finding was included as EPE.

Our study is in accordance with authors that consider extent of EPE or PSM an important information in the pathology report. Diffuse EPE or PSM were significantly associated with shorter time of TBR in univariate analysis, however, only diffuse PSM was significantly associated with TBR in univariate $(p<0.001)$ and multivariate analysis ( $p<0.001)$. Diffuse PSM was the strongest and an independent predictor of TBR in our cohort of patients. The incidence of PSM in the literature ranges from $16 \%$ to $50 \%$ (34). In our study the incidence was $46.5 \%$. One of the largest potential sources of discrepancy for incidence of PSM is the different methods used to process the radical prostatectomy specimens. It is also worth mention that positive surgical margins result of surgical factors more than biology of disease.

\section{Tumor extent on needle prostatic biopsies}

Recent efforts have focused on incorporating prostate needle biopsy measurements as an adjunct to improve pretreatment risk stratification (35-38). However, it is controversial which is the best predictor method (16-18). Bismar et al. (18) studied the prediction of pathologic stage in a screening population of multiple measures of carcinoma on prostate needle biopsy tissue. In univariate analysis all measures were significantly associated with pathologic stage $>\mathrm{T} 2$ but in multivariate analysis the percentage of positive cores was the strongest predictor.

Brimo's et al. (16) study is the only one that compared different methods of measurement of carcinoma on prostate needle biopsy. In univariate analysis, the percentage of cores with carcinoma was found to be the pathological preoperative variable that was most significantly associated with pathological stage $>$ pT2. In multivariate analysis, the greatest length and percentage of cancer in a single core, and the total percentage of cancer in all cores were most significant. Length and percentage of carcinoma in all cores, and percentage of number of cores with carcinoma were significantly associated to biochemical recurrence in univariate analysis. Multivariate analysis could not be conducted. 
In our study, except for maximum percentage of cancer per core and number of cores with cancer all other methods were significantly predictive of TBR using the curves of Kaplan-Meier. Using the Cox univariate analysis, all measures were statistically predictive of risk to TBR except maximum extent and percentage of cancer per core. The strongest predictor was percentage of cancer in all cores, however was not an independent predictor of shorter time of TBR in multivariate analysis.

All methods for measurement are simple and may be done in the daily practice of the surgical pathologist. However, they are not equivalent in application because measuring with an ocular micrometer foci of carcinoma can be time consuming. Total number and percentage of positive cores are the easiest way of evaluation accessible to all pathologists, and in our study were statistically significant in univariate analysis.

In summary, age and race were not significantly associated with TBR after surgery, however other more powered studies could show significance. Tumor extent evaluation in the surgical specimen was predictive of TBR in univariate analysis but not in multivariate analysis favoring that this time consuming report does not add additional information to other well established predictive findings. The higher predictive value of Gleason score $4+3=7$ vs $3+4=$ 7 disclosed the importance of grade 4 as the predominant pattern and favors a 4 score prognostic grouping: $\leq 6,3+4=7,4+3=7$, and $\geq 8$. Extent of EPE or PSM is an important information in the pathology report. Diffuse EPE or PSM were significantly associated with TBR in univariate analysis and diffuse PSM was independent and the strongest predictor of shorter time to BR in multivariate analysis. Most tumor extent evaluations on needle biopsies were predictive of TBR, however, maximum percentage of cancer in all cores was the strongest predictor. While shedding light to important and controversial predictors of biochemical recurrence after radical prostatectomy among Latin Americans, limitations of this study are the relatively short follow-up and the retrospective design, even in a prospectively collected database.

\section{ABBREVIATIONS}

PSA = prostate specific antigen;

$\mathrm{SD}=$ standard deviation;

$\mathrm{CI}=$ confidence interval;

$\mathrm{RP}=$ radical prostatectomy;

$\mathrm{BR}=$ biochemical recurrence;

$\mathrm{TBR}=$ time to biochemical recurrence;

$\mathrm{EPE}=$ extraprostatic extension;

$\mathrm{PSM}=$ positive surgical margin

\section{CONFLICT OF INTEREST}

None declared.

\section{REFERENCES}

1. Cookson MS, Aus G, Burnett AL, Canby-Hagino ED, D'Amico AV, Dmochowski RR, et al.: Variation in the definition of biochemical recurrence in patients treated for localized prostate cancer: the AmericanUrological Association Prostate Guidelines for Localized Prostate Cancer Update Panel report and recommendations for astandard in the reporting of surgical outcomes. J Urol. 2007; 177: 540-5.

2. Epstein JI, Amin M, Boccon-Gibod L, Egevad L, Humphrey PA, Mikuz G, et al.: Prognostic factors and reporting of prostate carcinoma in radical prostatectomy and pelvic lymphadenectomy specimens. Scand J Urol Nephrol Suppl. 2005; 34-63.

3. Carter HB, Epstein JI, Partin AW: Influence of age and prostatespecific antigen on the chance of curable prostate cancer among men with nonpalpabledisease. Urology. 1999; 53: 126-30.

4. Herold DM, Hanlon AL, Movsas B, Hanks GE: Age-related prostate cancer metastases. Urology. 1998; 51: 985-90.

5. Bauer JJ, Connelly RR, Seterhenn IA, Deausen J, Srivastava $S$, McLeod DG, et al.: Biostatistical modeling using traditional preoperative and pathological prognostic variables in the selection of men at highrisk for disease recurrence after radical prostatectomy for prostate cancer. J Urol. 1998; 159: 929-33.

6. Catalona WJ, Smith DS: Cancer recurrence and survival rates after anatomic radical retropubic prostatectomy for prostate cancer: intermediate-term results. J Urol. 1998; 160: 2428-34.

7. Evans S, Metcalfe C, Ibrahim F, Persad R, Ben-Shlomo Y: Investigating Black-White differences in prostate cancer prognosis: A systematic review and meta-analysis. Int $\mathrm{J}$ Cancer. 2008; 123: 430-5.

8. Kim HS, Moreira DM, Jayachandran J, Gerber L, Bañez LL, Vollmer RT, et al.: Prostate biopsies from black men express higher levels of aggressive disease biomarkers than prostate biopsies from whitemen. Prostate Cancer Prostatic Dis. 2011; 14: $262-5$ 
9. Powell IJ, Bock CH, Ruterbusch JJ, Sakr W: Evidence supports a faster growth rate and/or earlier transformation to clinically significant prostate cancer in black than inwhite American men, and influences racial progression and mortality disparity. J Urol. 2010; 183: 1792-6.

10. Cross CK, Shultz D, Malkowicz SB, Huang WC, Whittington $\mathrm{R}$, Tomaszewski JE, et al.: Impact of race on prostate-specific antigen outcome after radical prostatectomy for clinically localized adenocarcinoma of the prostate. J Clin Oncol. 2002; 20: 2863-8.

11. Freedland SJ, Jalkut M, Dorey F, Sutter ME, Aronson WJ: Race is not an independent predictor of biochemical recurrence after radical prostatectomy in an equal access medical center.Urology. 2000; 56: 87-91.

12. Paschoalin EL, Martins AC, Pastorello M, Sândis KA, Maciel LM, Silva WA Jr, et al.: Racial influence on the prevalence of prostate carcinoma in Brazilian volunteers. Int Braz J Urol. 2003; 29: 300-5.

13. Barros MS, Silva VR, Santos GB, Hughes A, Silveira MA: Prevalence of prostate adenocarcinoma according to race in an university hospital. Int Braz J Urol. 2003; 29: 306-11; discussion 312 .

14. Romero FR, Romero AW, Almeida RM, Tambara Filho R: The prevalence of prostate cancer in Brazil is higher in Black men than in White men: systematic review and meta-analysis. Int Braz J Urol. 2012; 38: 440-7.

15. Romero FR, Romero AW, de Almeida RM, de Oliveira FC Jr, Tambara Filho R: The significance of biological, environmental, and social risk factors for prostate cancer in a cohort study in Brazil. Int Braz J Urol. 2012; 38: 769-78.

16. Brimo F, Vollmer RT, Corcos J, Kotar K, Bégin LR, Humphrey $P A$, et al.: Prognostic value of various morphometric measurements of tumour extent in prostate needle core tissue. Histopathology. 2008; 53: 177-83.

17. Epstein JI, Potter SR: The pathological interpretation and significance of prostate needle biopsy findings: implications and current controversies. J Urol. 2001; 166: 402-10.

18. Bismar TA, Lewis JS Jr, Vollmer RT, Humphrey PA: Multiple measures of carcinoma extent versus perineural invasion in prostate needle biopsy tissue in prediction ofpathologic stage in a screening population. Am J Surg Pathol. 2003; 27: 432-40.

19. Humphrey PA, Vollmer RT: Intraglandular tumor extent and prognosis in prostatic carcinoma: application of a grid method to prostatectomy specimens. Hum Pathol. 1990; 21: 799-804.

20. Salomon L, Levrel O, Anastasiadis AG, Irani J, De La Taille A, Saint $F$, et al.: Prognostic significance of tumor volume after radical prostatectomy: a multivariate analysis of pathological prognosticfactors. Eur Urol. 2003; 43: 39-44.

21. Oefelein MG, Smith ND, Grayhack JT, Schaeffer AJ, McVary $\mathrm{KT}$ : Long-term results of radical retropubic prostatectomy in men with high grade carcinoma of the prostate. J Urol. 1997; 158: $1460-5$.
22. Han M, Partin AW, Pound CR, Epstein JI, Walsh PC: Longterm biochemical disease-free and cancer-specific survival following anatomic radical retropubic prostatectomy. The 15-year Johns Hopkins experience. Urol Clin North Am. 2001; 28: 555-65.

23. Chan TY, Partin AW, Walsh PC, Epstein Jl: Prognostic significance of Gleason score $3+4$ versus Gleason score $4+3$ tumor at radical prostatectomy. Urology. 2000; 56: 823-7.

24. Sung MT, Lin H, Koch MO, Davidson DD, Cheng L: Radial distance of extraprostatic extension measured by ocular micrometer is an independent predictor of prostate-specific antigen recurrence: A new proposal for the substaging of pT3a prostate cancer. Am J Surg Pathol. 2007; 31: 311-8.

25. Shikanov S, Song J, Royce C, Al-Ahmadie H, Zorn K, Steinberg $\mathrm{G}$, et al.: Length of positive surgical margin after radical prostatectomy as a predictor of biochemical recurrence. $\mathrm{J}$ Urol. 2009; 182: 139-44.

26. van Oort IM, Bruins HM, Kiemeney LA, Knipscheer BC, Witjes JA, Hulsbergen-van de Kaa CA: The length of positive surgical margins correlates with biochemical recurrence after radical prostatectomy. Histopathology. 2010; 56: 464-71.

27. Magi-Galluzzi C, Evans AJ, Delahunt B, Epstein Jl, Griffiths $D F$, van der Kwast TH, et al.: International Society of Urological Pathology (ISUP) Consensus Conference on Handling and Staging of RadicalProstatectomy Specimens. Working group 3: extraprostatic extension, lymphovascular invasion and locally advanceddisease. Mod Pathol. 2011; 24: 26-38.

28. Tan PH, Cheng L, Srigley JR, Griffiths D, Humphrey PA, van der Kwast TH, et al.: International Society of Urological Pathology (ISUP) Consensus Conference on Handling and Staging of RadicalProstatectomy Specimens. Working group 5: surgical margins. Mod Pathol. 2011; 24: 48-57.

29. Billis A, Magna LA, Ferreira U: Correlation between tumor extent in radical prostatectomies and preoperative PSA, histological grade, surgical margins, andextraprostatic extension: application of a new practical method for tumor extent evaluation.Int Braz J Urol. 2003; 29: 113-9; discussion 120.

30. Epstein JI, Allsbrook WC Jr, Amin MB, Egevad LL; ISUP Grading Committee: The 2005 International Society of Urological Pathology (ISUP) Consensus Conference on Gleason Grading of ProstaticCarcinoma. Am J Surg Pathol. 2005; 29: 1228-42.

31. Parker CC, Gospodarowicz M, Warde P: Does age influence the behaviour of localized prostate cancer? BJU Int. 2001; 87: 629-37.

32. Latini DM, Elkin EP, Cooperberg MR, Sadetsky N, Duchane J, Carroll PR: Differences in clinical characteristics and disease-free survival for Latino, African American, and nonLatino white men withlocalized prostate cancer: data from CaPSURE. Cancer. 2006; 106: 789-95.

33. Epstein Jl: Pathologic assessment of the surgical specimen Urol Clin North Am. 2001; 28: 567-94. 
34. Watson RB, Civantos F, Soloway MS: Positive surgical margins with radical prostatectomy: detailed pathological analysis and prognosis. Urology. 1996; 48: 80-90.

35. D'Amico AV, Whittington R, Malkowicz SB, Schultz D, Fondurulia J, Chen MH, et al.: Clinical utility of the percentage of positive prostate biopsies in defining biochemical outcome after radical prostatectomyfor patients with clinically localized prostate cancer. J Clin Oncol. 2000; 18: 1164-72.

36. Grossfeld GD, Latini DM, Lubeck DP, Broering JM, Li YP, Mehta SS, et al.: Predicting disease recurrence in intermediate and high-risk patients undergoing radical prostatectomy using percentpositive biopsies: results from CaPSURE. Urology. 2002; 59: 560-5.

37. Presti JC Jr, Shinohara K, Bacchetti P, Tigrani V, Bhargava V: Positive fraction of systematic biopsies predicts risk of relapse after radical prostatectomy. Urology. 1998; 52: 1079-84.
38. Freedland SJ, Csathy GS, Dorey F, Aronson WJ: Percent prostate needle biopsy tissue with cancer is more predictive of biochemical failure or adverse pathology after radical prostatectomy than prostate specific antigen or Gleason score. J Urol. 2002; 167: 516-20.

Correspondence address: Athanase Billis, MD, PhD

Depatment of Anatomic Pathology School of Medical Sciences State University of Campinas (Unicamp) Rua Tessália Vieira de Camargo, 126

Campinas, SP, 13083-887, Brazil

Fax: +55 19 3289-3897

E-mail: athanase@fcm.unicamp.br 